Arteterapia. Papeles de arteterapia y educación para inclusión social ISSN-e 1988-8309

https://dx.doi.org/10.5209/arte.65097

\title{
Supervisión basada en el arte, a través de creación de respuesta artística. Valoración de su uso en una formación de arteterapia
}

\author{
Norma Irene García-Reyna ${ }^{1}$
}

Recibido: 25 noviembre 2018 / Aceptado: 5 de junio de 2019

Resumen. El uso del arte y la creación artística dentro del espacio de supervisión, son elementos comúnmente referenciados en otros países; sin embargo, no lo son tanto en nuestro territorio nacional. Tampoco contamos con una evaluación formal sobre su uso explícito. Este trabajo describe una experiencia de supervisión basada en el arte, donde las respuestas artísticas fueron usadas como un método de trabajo para la exploración, cuidado y expresión de la práctica clínica. El estudio fue desarrollado dentro del contexto académico de un máster de arteteterapia, durante dos cursos consecutivos. Se ofrecen resultados cuantitativos y cualitativos que muestran resultados eficaces de la supervisión basada en el arte, así como ejemplos de respuestas artísticas creadas por las alumnas y la supervisora. Fueron evaluadas 11 respuestas de alumnas de primero y segundo curso, que recibieron esta modalidad de supervisión. Se incluye una discusión sobre los resultados, así como recomendaciones para el uso adecuado de esta metodología.

Arteterapia: Supervisión basada en el arte; Supervisión. Arte; Respuesta artística.

\section{[en] Art-based supervision through response art. Assessment of its use in an art therapy training}

\begin{abstract}
The use of art and artistic creation within the supervision space are elements commonly referenced in other countries; they are not so much in our national territory. We also do not have a formal evaluation of its explicit use. This work describes an experience of art-based supervision, where response art was used as a working method for the exploration, care and expression of clinical practice. The study was developed within the academic context of an art therapy master's degree, during two consecutive courses. Quantitative and qualitative data are offered that show effective results of the art-based supervision, as well as examples of response art created by the students and supervisor. Eleven responses from first- and second-year students, who received this supervision modality were evaluated. A discussion on the results is included as well as recommendations for the accurate use of this methodology.
\end{abstract}

Art therapy: Art-based supervision; Supervision. Art; Artistic response.

Sumario. 1. Introducción. 2. Marco teórico. 2.1. Supervisión basada en el arte. 2.2. Respuesta artística por arteterapeutas. 2.3. Supervisión en arteterapia en España. 3. Contexto de la investigación. 4. Preguntas de investigación. 5. Objetivos. 5.1 Objetivo principal. 5.2 Objetivos específicos. 6. Métodos y participantes. 7. Espacio de supervisión. 8. Resultados. 8.1 Resultados Cuantitativos. 8.2 Respuestas cualitativas y artísticas. 9. Discusión. 10. Conclusiones.

1 Metáfora, Escuela de Estudios de Arte y Arteterapia. Docente y supervisora de prácticas de arteterapia E-Mail: normairene.garcia@metafora.org 
Cómo citar: García-Reyna, N. I. Supervisión basada en el arte, a través de creación de respuesta artística. Valoración de su uso en una formación de arteterapia en Arteterapia. Papeles de arteterapia y educación para inclusión social 14, 2019, 201-220.

\section{Introducción}

La supervisión durante la formación de arteterapia es fundamental para la enseñanza, a fin de garantizar una práctica clínica responsable. Es a través de la experiencia de supervisión donde se puede llegar al aprendizaje profundo y cuidar la calidad de los servicios prestados por arteterapeutas en formación, para que puedan ofrecer la intervención mas adecuada.

La supervisión basada en el arte (SBA) es aquella en la que los procesos y creaciones artísticas de los/as supervisadas/os se utilizan para procesar la práctica clínica (Miller y Robb, 2017). Descrita como una práctica útil para el desarrollo del aprendizaje, la promoción del autoconocimiento y la autoconciencia; así como para un desarrollo de la profesión más integrada (Fish, 2008; Miller, 2012). La práctica de SBA puede ser realizada a partir la respuesta artística (RA), término utilizado para referirse a los objetos artísticos creados por arteterapeutas como práctica reflexiva en respuesta a las sesiones clínicas, a fin de lidiar con el material surgido.

En mi función como supervisora de una formación de arteterapia, fomento cada vez más, el uso de las imágenes dentro del espacio de supervisión. Las imágenes de clientes, las de estudiantes y ocasionalmente las mías, han sido usadas como componentes centrales con el fin de explorar y contener la experiencia clínica.

En este trabajo se valora una experiencia de SBA a través de RA, en un máster de arteteterapia. Está basado en el modelo de trabajo de Fish (2008) descrito posteriormente. Se realizaron modificaciones al protocolo, a fin de adaptarlo a nuestro plan de estudios y experiencia académica.

Se ofrecen resultados cuantitativos y cualitativos que muestran la eficacia de esta modalidad de aprendizaje; ejemplos de RA para ejemplificar su uso; una discusión sobre los resultados, así como recomendaciones para llevarla a cabo de forma adecuada. La evaluación fue realizada a partir de los resultados encontrados en las respuestas de estudiantes que participaron en esta modalidad de supervisión.

La pregunta de investigación fue: ¿qué valor añadido puede tener la creación de RA para su uso en supervisión, a fin de apoyar la práctica clínica de estudiantes en formación en arteterapia?

\section{Marco teórico}

\subsection{Supervisión basada ene el arte}

La integración del arte dentro de la supervisión, puede complementarse de enfoques teóricos haciendo que sea más efectiva (Berger, 2017). La SBA se puede definir como la creación de conocimiento utilizando medios artísticos, a fin de explorar, contener y expresar la práctica clínica.

Expresada de esta manera la SBA puede apoyarse en lo que comenta Omenat (2011), quien refiere que la supervisión ha de ser una ayuda creativa apoyada con 
la obra, imprescindible en nuestra profesión, para preservarnos y preservar a las personas con las que trabajamos.

Miller y Robb (2017) refieren dos modelos primarios del uso del arte dentro del espacio de supervisión, uno de ellos es la utilización de la imagen de pacientes como componente central del proceso de supervisión y el otro la SBA, donde las creaciones artísticas de las/los aprendices son usadas para procesar la experiencia clínica. Estas creaciones han sido consideradas como parte esencial en la supervisión (Carpendale, 2011; Fish, 2012; Guiffrida, Jordan, Saiz y Barnes, 2007; Wadeson, 2003).

Aunque poco documentado, existen algunas publicaciones sobre el uso explícito de la creación de arte dentro del espacio académico de supervisión, con evaluación formal sobre ello (Fish, 2008; McNamee y McWey, 2004; Miller, 2002; Miller y Robb, 2017), para estas autoras la SBA es una práctica que promueve una identidad profesional más integrada; mayor autoconsciencia y autoconocimiento. Para Miller y Robb (2017) se integra el aprendizaje artístico, emocional y didáctico en la capacitación clínica, fomentando una conciencia compasiva de las/los supervisadas/os.

Berger (2017) refiere que la SBA puede fortalecer al artista que hay dentro del/ la terapeuta, abriendo el abanico de posibilidades creativas, ofreciendo fe en sus herramientas e inspiración para usarlas, complementándose de enfoques teóricos para aumentar su efectividad.

Malchiodi y Riley, 1996 (citadas por Miller, 2012), refieren que el propósito de la supervisión en las formaciones de arteterapia es guiar a las/los estudiantes en el diseño de estrategias terapéuticas exitosas, así como en el desarrollo de una identidad profesional; por lo que es necesario incluir el arte como un componente esencial (Miller, 2012); siendo como dice Allen (1995), una forma de conocimiento y un medio de descubrimiento (citado en Kapitan, 2017). Omenat (citada en Serrano, 2017) nos recuerda la necesidad de la obra plástica en supervisión, como elemento de comunicación en sí mismo, que debe de estar presente y ser escuchado.

Deaver y Shiflett (2011) mencionan que la creación artística enfocada y consciente es en sí misma, un esfuerzo constructivista y generador de significado. La creación artística por si sola, puede no ser suficiente para la construcción del conocimiento. Es necesario el acto de la reflexión para que la práctica del arte sea una oportunidad para generar el entendimiento, esta oportunidad puede darse en los espacios de supervisión.

Miller (2012) y Miller y Robb (2017), describen un modelo de SBA que combina el conocimiento clínico con la conciencia arquetípica, el cual surge del proceso creativo a través de la intervención en un solo lienzo durante un semestre educativo. El modelo está inspirado en la lucha artística de "El Duende", término español usado en las artes y definido por García Lorca (2003) como un poder misterioso de creación que sentimos pero que es difícil de explicar. Con este modelo de supervisión las autoras han encontrado que las/los alumnas/os desarrollan habilidades para abordar preocupaciones de supervisión tangibles e intangibles. Este modelo se desarrolla actualmente en algunas formaciones de arteterapia en EUA.

Guiffrida et al. (2007) y Carpendale et al. (2011) describen que el uso de la metáfora en supervisión ofrece un gran potencial para facilitar el crecimiento y desarrollo. Mencionan que el proceso creativo dentro de este espacio, ayuda a desarrollar la auto reflexión y auto resolución de problemas, dando la oportunidad de expresar emociones difíciles de articular y permitiendo que se manifieste contenido inconsciente latente. 


\subsection{Respuesta artística por arteterapeutas}

La práctica de SBA puede ser realizada a partir de creación de respuestas artísticas (RA), término utilizado para referirse a los objetos artísticos creados por arteterapeutas, como práctica reflexiva en respuesta a las sesiones clínicas para lidiar con el material surgido (Fish, 2008 y 2012; García-Reyna, 2017; Gilroy, 1989; Kielo, 1988; Marano-Geiser, 1990; Wadeson, 2003); para esta última autora la RA es la herramienta principal en la práctica de la SBA.

La RA ha sido descrita como herramienta útil para la reflexión, comprensión y avance en el trabajo clínico (Crawford, Solis y Pfister, 2014; Fish, 2008; Miller, 2017; Wadeson, 2003); como contenedora de sentimientos difíciles e intensos, facilitando acceder y enfrentarse a ellos (Brown, Meyerowitz-katz y Ryde, 2003; Fish 2012; Marano-Geiser, 1990; Miller y Robb, 2017; Moon, 1999); aportando claridad y produciendo un efecto calmante (Fish, 2012; Wadeson, 2003); como herramienta indispensable en la formación y mantenimiento de la identidad como artista y arteterapeuta (Crawford et al. 2014; Gilroy, 1989; Rogers, 2002; Wadeson, 2003) entre otros beneficios.

El primer estudio al respecto que aparece en la literatura es el de Kielo (1988), un trabajo cualitativo basado en entrevistas realizadas a 11 arteterapeutas, con el fin de explorar el uso de las imágenes creadas después de las sesiones con clientes para hacer frente al material clínico. Sus resultados mostraron cinco usos básicos:

1) El desarrollo de la empatía a través de la réplica de imágenes de clientes.

2) Aclaración de los sentimientos de arteterapeutas.

3) Exploración del preconsciente e inconsciente.

4) Diferenciación de los sentimientos de arteterapeutas por parte del cliente.

5) Análisis de la relación terapéutica.

Diferentes arteterapeutas han descrito que realizar RA dentro del espacio de supervisión facilita la capacidad de autoconciencia y reflexión (Brown et al., 2003; Carpendale, 2011; Deaver et al., 2011; Fish, 2008; Fish, 2012; Guiffrida, Jordan, Saiz y Barnes, 2007; Miller, 2012; Miller y Robb, 2017; Wadeson, 2003), ayudando a la formación y mantenimiento de la doble identidad como artista y arteterapeuta (Crawford et al. 2014; Gilroy 1989; Rogers 2002; Wadeson 2003). Carpendale (2011) en su trabajo expone una serie de ejercicios para realizar RA dentro del espacio de supervisión, hace referencia a sugerencias de Kramer (1986), Schaverien (1992) y de su propia experiencia (Carpendale 2011).

Fish (2008) realizó un estudio de metodología mixta sobre el uso de RA dentro del espacio de supervisión analizando respuestas de 19 estudiantes. Durante la supervisión, las alumnas y la autora realizaron RA dentro y fuera del espacio de supervisión, para posteriormente ser discutidas en el grupo.

Al finalizar el semestre educativo, las/los estudiantes completaron un cuestionario y escribieron sobre la experiencia de SBA. La mayoría de participantes estuvieron de acuerdo en que la creación de arte y la discusión fue útil, que valía la pena tomar ese tiempo dentro del espacio de supervisión. Sin embargo, hubo participantes que deseaban un supervisión más didáctica y basada en discusiones clínicas. Otras/ os participantes expresaron su preocupación por mostrar sus RA, ya que en ocasiones surgían temas demasiado personales para compartir. 
Con su trabajo la autora pudo mostrar la utilidad de esta metodología, sin embargo, advierte que hacer RA en supervisión, es una herramienta, no una panacea. Comenta que esta no soluciona todos los problemas y sugiere buscar un equilibrio entre el uso efectivo de la RA y la parte teórica y verbal dentro de este espacio de aprendizaje. También recomienda crear una atmósfera de apoyo para disminuir ansiedad y crear la suficiente confianza entre las/los estudiantes. Miller et al. (2017) refiere al respecto que la supervisión que promueve alianzas dentro de un ambiente grupal, nutre la capacidad de tener el valor de exponer las vulnerabilidades, cometer errores y asumir riesgos, los cuales son claves para el crecimiento clínico.

Brown, Meyerowitz-katz y Ryde (2003), refieren algunas cualidades importantes para el establecimiento de una relación de supervisión segura, como la construcción de confianza y respeto que implica honestidad por parte del/la supervisor/a; el uso de su propia experiencia; luchas, confusiones y desconocimiento. Así como la escucha sin prejuicios y el saber percibir la propia contratransferencia (Gordon, 1992 citado en Brown et. al., 2003).

\subsection{Supervisión en arteterapia en España}

Aunque en otros países la creación artística para explorar problemas clínicos dentro de los espacios de supervisión ha sido un pilar en las formaciones de arteterapia desde hace tiempo, en España hemos tenido una experiencia de supervisión predominantemente verbal. Definir a qué llamamos supervisión dentro de las formaciones de arteterapia, así como las maneras de desarrollarla, son aspectos que quedan por formalizar a partir del encuentro entre profesionales y trabajos de investigación.

Actualmente se le da cada vez más importancia a las RA creadas por estudiantes fuera del espacio de supervisión y traídas como material de apoyo en la exposición de casos clínicos (García-Reyna, 2017). Lo que permanece sin ser habitual, es la creación de RA dentro de este espacio educativo. El origen de la profesión en nuestro país es relativamente nuevo (Marxen, 2011; García-Reyna, 2017), queda mucho por explorar. Uno de los motivos por el cual surge este trabajo, es por la necesidad de fortalecer la identidad de arteterapia dentro de nuestro ámbito territorial.

\section{Contexto de la investigación}

A pesar de que durante mi instrucción como arteterapeuta, la experiencia educativa de supervisión fue predominantemente verbal, tuve la oportunidad de iniciarme en el uso RA de la mano de Carles Ramos (2010). Las RA formaron parte indispensable del material de mis prácticas como estudiante, me ayudaron a contener y explorar mi trabajo clínico, sin embargo por aquel entonces las RA se usaban solo de forma tímida en supervisión, por lo que permanecieron como producciones artísticas sin compartir.

Actualmente, gracias a la lectura bibliográfica y la formación continuada, he ido introduciendo cada vez más, la imagen como parte esencial de la supervisión. En un seminario, Val Huet $(2016)^{2}$ nos animó a tomar en cuenta la imagen como "el corazón" de nuestra profesión, alentándonos a crear RA dentro del espacio de super-

2 Huet, V., (2016). Seminario de teoría de la Supervisión en Arteterapia. Metáfora. Escuela de Arte y Arte contemporáneo. Barcelona 
visión, no sin antes señalar la importancia de tener siempre en mente al/la usuario/a y su obra en el momento de creación artística.

El objetivo de la supervisión señaló, es que los/las clientes tengan la intervención más adecuada, todo se enfoca ellos/ellas; la persona supervisada es importante, sin embargo, por cuestión de prioridades y para evitar que el espacio se convierta en terapia personal, debemos enfocarnos en las/los usurarias/os. Por ello, cuando se realiza RA es importante recordar que, es un acto consciente de reflexión, un proceso de creación pensando en la persona usuaria.

\section{Preguntas de investigación}

De primera mano he conocido la utilidad de la creación de RA, herramienta que utilizo frecuentemente, sin embargo me hacía diferentes preguntas: ¿sería útil de la misma manera para las alumnas en formación?, ¿Es posible introducir la SBA de manera formal en nuestros espacios de formación?, ¿De qué manera podría ser utilizada la imagen una vez hecha, para que fuera de utilidad en sus prácticas clínicas como instrumentos de exploración de su trabajo?, ¿qué valor añadido puede tener la creación de RA, para su uso en supervisión a fin de apoyar la práctica clínica de estudiantes de arteterapia?

\section{Objetivos}

De los antecedentes antes presentados y partiendo de estas cuestiones se plantearon los siguientes objetivos:

\subsection{Objetivo principal}

Valorar una experiencia de SBA a través del uso de RA, con las estudiantes de primero y segundo año, en una formación de arteterapia.

\subsection{Objetivos específicos}

1. Valorar la utilidad de RA creadas fuera del espacio de supervisión, como apoyo explicativo en el espacio de supervisión.

2. Evaluar la utilidad de la creación de RA dentro del espacio de supervisión.

3. Conocer el beneficio de recibir RA por parte de las compañeras del grupo de supervisión.

4. Estimar la utilidad de realizar RA hacia las compañeras como un método de retroalimentación.

\section{Métodos y participantes}

En este trabajo se evalúo de forma cuantitativa y cualitativa una experiencia de SBA a través del uso de RA, realizadas por las estudiantes y por la supervisora. Está basado en el protocolo de Fish (2008), el cual se ha referido anteriormente; se realizaron 
modificaciones a fin de adaptarlo a nuestro plan de estudios. Para este trabajo se utilizaron 7 de los 10 ítems propuestos por la autora (Ver tabla 1).

Las técnicas utilizadas para la evaluación han incluido el uso de métodos cuantitativos a través de un cuestionario de opinión tipo Lickert; así como cualitativos, con la incorporación de una serie de preguntas abiertas. Las respuestas han sido analizadas mediante un análisis de contenido verbal basado en el propuesto por Hervás Hermida (2018), el cual ha consistido en un proceso de revisión sistemática; categorización de las respuestas; suma categórica y síntesis.

La categorización se realizó a partir de categorías previas basadas en el marco teórico y prefijadas por la propia pregunta, así como atendiendo a las categorías emergentes en las respuestas de las estudiantes.

Fue realizada una búsqueda de aspectos de desconfirmantes, diferentes a la tendencia para profundizar y comprender el significado de las respuestas de acuerdo al contexto de la investigación. Se realizó también un trabajo de triangulación contrastando los datos obtenidos, con el marco teórico, así como una revisión de los resultados por parte de una investigadora externa ${ }^{3}$.

Al finalizar el año escolar se les envió a las alumnas un cuestionario autoaplicado, diseñado mediante la plataforma online Google Form. Se les invitó a contestarlo de forma voluntaria y anónima a fin de recoger su valoración. De los resultados de este cuestionario surgen los datos presentados, los cuales han sido utilizados para evaluar esta metodología de trabajo.

Por otro lado, también se les pidió (si lo deseaban) compartir aquellas RA creadas dentro o fuera del espacio de supervisión, que hubieran sido de especial ayuda en su práctica, acompañada de un comentario al respecto sobre la imagen. Se muestran en este trabajo como un complemento al cuestionario, a fin de facilitar la comprensión de la lectura, ya que las RA son el objeto de la investigación. Se exponen todas las imágenes enviadas por las alumnas.

La incursión que he realizado ha sido de forma cautelosa, ya que como se menciona anteriormente pertenezco a una generación en la que el modo de supervisión verbal ha sido la predominante. A diferencia de Fish, no mostré mis RA creadas fuera del espacio de supervisión. Las alumnas crearon RA dentro y fuera del espacio de supervisión, yo como supervisora realice RA dentro de este espacio junto con las alumnas, a fin de ofrecer retroalimentación a la estudiante en turno que exponía su práctica clínica para supervisar. Esta práctica fue un complemento de exploración, cuidado y expresión de su trabajo clínico verbal.

Las respuestas al cuestionario presentadas en este trabajo son totalmente anónimas, en cambio las imágenes y comentarios extras compartidos por algunas participantes están referenciados con sus nombres reales, una decisión tomada por ellas a fin de reconocer su autoría. Se les ha ofrecido previo a la publicación, la posibilidad de negociar sobre sus comentarios, han tenido la posibilidad de volver a leer y corregir, dando el consentimiento para su divulgación ${ }^{4}$.

Las alumnas respondieron a un cuestionario elaborado con la escala de Likert con 5 posibilidades de respuesta, especificando el nivel de acuerdo o desacuerdo con afirmaciones expuestas ( $1=$ Muy en desacuerdo; $2=$ En desacuerdo; $3=$ No estoy

Dra. Lucía Hervás Hermida, Universidad Autónoma de Madrid.

Se cuenta con el consentimiento por escrito de las participantes. 
segura; 4 = De acuerdo; 5 = Totalmente de acuerdo). El cuestionario está compuesto por 7 afirmaciones (Ver tabla 1) sobre la SBA.

De este instrumento surgieron los datos de orden cuantitativo; también se les invitó a realizar comentarios cualitativos sobre las afirmaciones 1- 4 y 7 . En la pregunta 8, se les invitó a expresar 4 ventajas de la RA como parte de sus prácticas (Tabla 2). Participaron 13 estudiantes, fueron evaluadas 11 respuestas, dos alumnas no contestaron el cuestionario; al ser de carácter anónimo no se conoció el motivo. Los grupos estuvieron compuestos por 6 estudiantes en el primer año y 7 en el segundo. Todas las participantes fueron mujeres con edades comprendidas entre 25 a 48 años.

Tabla 1. Ítems evaluados en el cuestionario a través de escala de Likert:

\section{Afirmaciones}

1. El énfasis en realizar RA y explorar las imágenes durante la supervisión es eficaz para supervisar.

2. Mostrar durante la supervisión mis RA realizadas fuera de la supervisión, ha sido útil para profundizar en explicar mi práctica clínica

3. La experiencia de que mis compañeras realizaran RA sobre mi práctica clínica para darme retroalimentación ha sido de utilidad para mi.

4. Las RA que yo realicé para mis compañeras para darles retroalimentación sobre su práctica clínica ha sido de utilidad para mí.

5. Realizar RA durante el tiempo de supervisión ayuda a explorar dudas.

6. Realizar RA es una forma de auto cuidado

7. Realizar trabajo artístico durante la supervisión quita un tiempo valioso para la discusión de otros aspectos (respuesta invertida).

\section{Cuestionario modificado de Fish (2008).}

Lectura de respuestas: $1=$ Muy en desacuerdo; 2 = En desacuerdo; 3 = no estoy segura; $4=$ De acuerdo; 5 = Totalmente de acuerdo.

\section{Espacio de supervisión}

El espacio de supervisión en nuestra escuela es ofrecido quincenalmente por un periodo de nueve meses (de octubre a junio), la duración de cada encuentro es de 3 horas y media, se realiza en formato grupal.

Además de supervisiones verbales todas las alumnas tuvieron la oportunidad de tener una SBA, en la cual después de la exposición del caso clínico sus compañeras; ella misma y la supervisora realizamos RA como devolución a su presentación. La consigna de creación fue, realizar una RA pensando en la exposición sobre el caso expuesto por la alumna supervisada en ese momento, es decir, crear con la atención enfocada en el/la usuario/a y en la estudiante supervisada, a fin de ofrecerle una retroalimentación y reflexión amplificada a través de RA sobre su trabajo.

El ejercicio completo tenía una duración aproximada de 1 hora y media, divida aproximadamente de la siguiente manera: 35 minutos de exposición del trabajo clínico; 25 minutos de creación artística (por todas las integrantes) y 30 minutos de 
reflexión a partir de las RA; esta ultima parte del ejercicio se realizaba disponiéndonos en círculo y mostrando al centro todas las producciones. Este modo de trabajo ofreció la posibilidad de dar y recibir retroalimentación a través de las RA realizadas por las compañeras, la supervisora y la propia alumna.

Para el grupo de primer año el inicio de esta metodología, se llevó a cabo a partir del tercer mes, ya que siguiendo las recomendaciones de otros autores, se puso énfasis en la importancia de crear primero un ambiente de confianza entre las personas que integran el grupo de supervisión. Presumí que este tiempo sería suficiente para que las integrantes del grupo se conocieran y se sintieran cómodas para la creación de RA delante de sus compañeras y de su supervisora. Las estudiantes de segundo año ya se conocían, por lo que se realizó RA al segundo encuentro, una vez fue explicado el proceso.

\section{Resultados}

\subsection{Resultados Cuantitativos}

Debido a la pequeña muestra (11), los resultados cuantitativos se ofrecen de forma descriptiva, realizando una evaluación de los datos para ofrecer una descripción narrativa. A continuación, se muestran las respuestas en función del grado de acuerdo o desacuerdo con la utilidad de la SBA. La Figura 1 muestra los resultados expresados en frecuencia y porcentaje para las respuestas a la escala Likert.

Figura 1. Respuestas a las afirmaciones del cuestionario de las alumnas. $(\mathrm{n}=11)$.

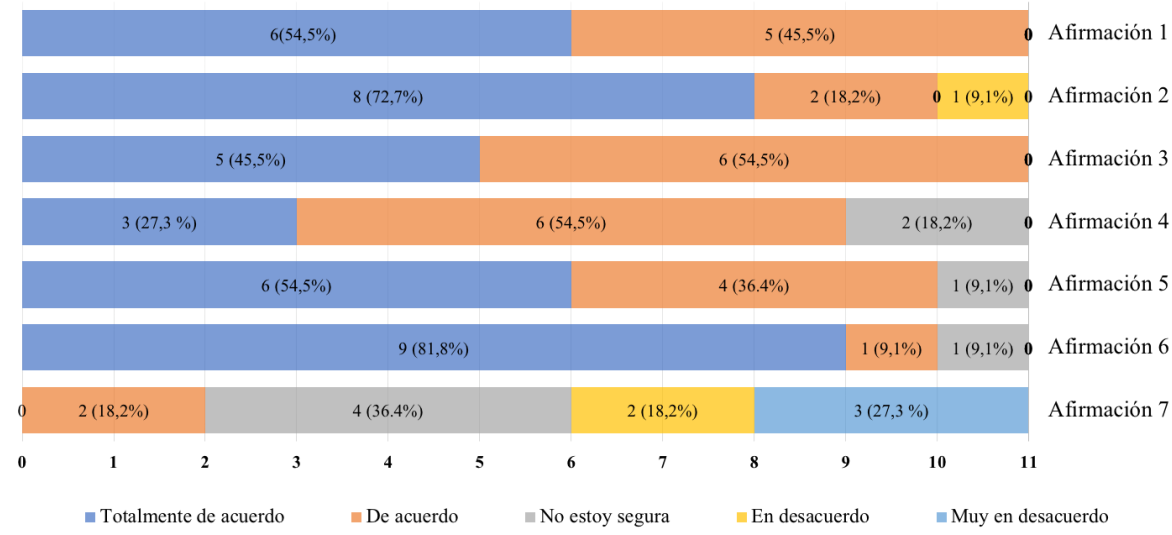

Gráfico de elaboración propia desde del cuestionario de evaluación, creado a partir de las opiniones de las alumnas. Escala tipo Likert con una lectura de respuesta entre "muy en desacuerdo" y "muy de acuerdo". La respuesta a la afirmación 7 es invertida.

Para los ítems $\mathrm{N}^{\mathrm{o}} 1$ y 3 , que se refieren a la utilidad de la creación y uso de la RA en el espacio de supervisión, todas las participantes refirieron estar de acuerdo o totalmente de acuerdo. Realizar RA y explorarlas dentro del espacio de supervisión para profundizar en su práctica clínica fue descrito como útil por la mayoría de las participantes (afirmación $\mathrm{N}^{\mathrm{o}} 2$ ); una alumna contestó no estar de acuerdo con ello. Dos alumnas refirieron no estar seguras con respecto a la utilidad de crear RA para sus compañeras (afirmación $\mathrm{N}^{\circ} 4$ ), el resto estuvo de acuerdo o totalmente de acuer- 
do. Para las afirmaciones $\mathrm{N}^{\circ} 5$ y 6 , sobre la utilidad como herramienta de auto cuidado y exploración de dudas, una alumna para cada ítem respondió no estar segura, el resto declararon estar de acuerdo o totalmente de acuerdo.

En general se observa una tendencia positiva en las posibilidades de respuestas, sin embargo, no todas valoraron el uso de la SBA en todas las circunstancias; a la declaración $\mathrm{N}^{\mathrm{o}} 7$, sobre el uso del tiempo de supervisión usado para creación artística, dos alumnas refirieron no estar de acuerdo y cuatro contestaron no estar seguras.

\subsection{Respuestas cualitativas y artísticas}

A continuación, se ofrecen los resultados cualitativos correspondientes a las afirmaciones $\mathrm{N}^{\mathrm{o}} 1-4$ y 7 de la escala de Likert (Tabla 1) y a la pregunta $\mathrm{N}^{\circ} 8$. Se intercalan con imágenes (Figuras 2-7) a modo de viñetas, las cuales han sido compartidas por algunas de las alumnas a fin de mostrar ejemplos de RA usadas en supervisión.

Afirmación 1. El énfasis en realizar $R A$ y explorar las imágenes durante la supervisión es eficaz para supervisar.

"Es un elemento diferente, como una respuesta en otro nivel que puede ayudar tanto a la persona que hace la respuesta (para entender a la persona y la situación) como la persona que la recibe". El proceso de categorización de las respuestas mostró que para la mayoría de las participantes fue una herramienta de utilidad en diferentes aspectos, el desarrollo de la comprensión fue la variable más relevante, refiriéndola cuatro personas como una metodología útil para el desarrollo del aprendizaje; cuatro la valoraron como una forma de trabajo diferente de apoyo en la comprensión hacia sus usuarias/as: “...vimos las situaciones problemáticas desde muchos ángulos diferentes y esto fue muy útil”"

Sin embargo, una estudiante refirió sentirse forzada, matizando que: "puede ser un recurso útil, pero no sistemático...", “A veces, me he forzado..." El proceso de supervisión cuenta con un calendario donde las alumnas tienen turnos para exponer sus casos, puede ser un factor que contribuya a la situación que la alumna refiere.

Afirmación 2. Mostrar durante la supervisión mis $R A$ realizadas fuera de la supervisión, ha sido útil para profundizar en explicar mi práctica clínica.

"Mis RA contienen información consciente e inconsciente... que canalizo en las obras al acabar las sesiones. Supervisar mis RA me ayuda a ver elementos inconscientes, importantes para la relación terapéutica, que de otra forma no podría ver". Solamente una alumna refirió no estar de acuerdo con esta afirmación, "me servía para capturar algo y compartirlo. No expresaba nada especial respecto a mi practica clínica, creo". Para tres resultó útil como herramienta de apoyo en comunicación, "Hace que las personas que están escuchando puedan entender mejor la información...”. Se observó que para tres personas fue de ayuda en la comprensión de contenidos inconscientes y cuestiones contratransferenciales; de apoyo en la comprensión de sus prácticas y la relación con usuarias/os. A modo de ejemplo se incluyen las viñetas 2 y 4.

Viñeta 1. Con una paciente me resultó útil hacer la respuesta artística (Figura 2) para fijar parte del contenido que la paciente 'ocultaba' en obras generalmente alegres, positivas y muy contenidas. Es una de las obras donde enseño la cara B 
de las sesiones. También el hacerla fue útil: romper el movimiento de la mano, la frágil línea de madera, y ver los trozos tirados en la mesa, me acercó a la vivencia de la paciente: en lo profundo, lo que ella no quería mostrar (o ver) estaba y le hacía difícil mantener una cara ordenada y lineal (Amaranta Amati).

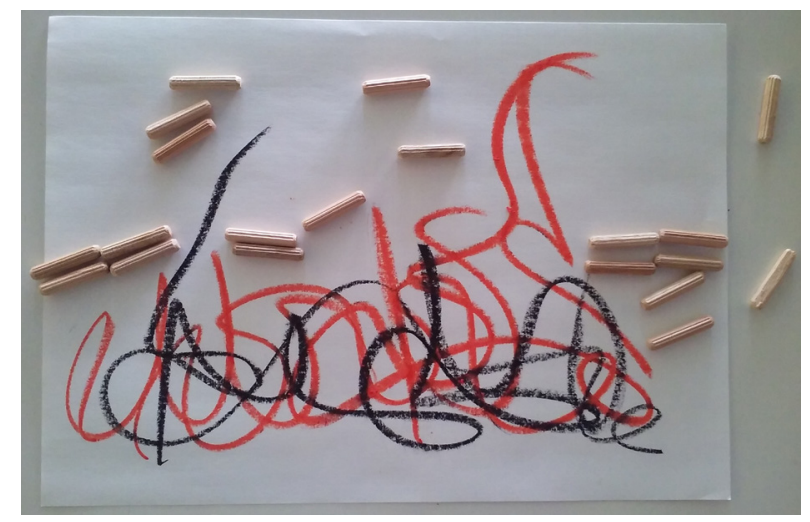

Figura 2. RA de Amaranta Amati, realizada fuera del espacio de supervisión, usada para explicación del caso.

Viñeta 2. ¡Fue una imagen útil (Figura 3) porque en supervisión me ofreció una manera de entender el "vacío" que sentía cuando todos (grupo de usuarios de práctica clínica), se querían llevar su obra a casa y no quedaba nada para mi! Tus palabras (supervisora) me fueron de ayuda para ser flexible con los usuarios y para sentirme a gusto con la "informalidad" de las sesiones con ese colectivo (discapacidad intelectual). Recuerdo que comentaste que es una forma de quererse llevar un poco de mi con ellos, esto me hizo sentir valorada por el grupo (Simona Alfano).

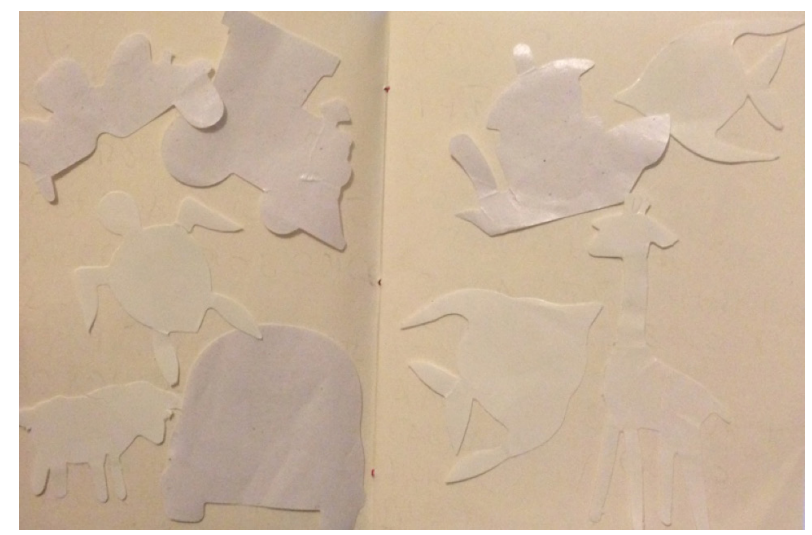

Figura 3. RA de Simona Alfano, realizada fuera del espacio de supervisión usada para explicación del caso. 
Afirmación 3. La experiencia de que mis compañeras realizaran $R A$ sobre mi práctica clínica para darme retroalimentación ha sido de utilidad para mi.

"Hacen que te des cuenta de la relación que tienes con el paciente, visto desde fuera. Es muy reconfortante". Recibir RA por parte de las compañeras fue una experiencia muy valorada, de acompañamiento, comprensión y contención; algunas refirieron poder "ver desde afuera" la situación, ofreciendo la oportunidad de entender aspectos de sí mismas, de sus usuarias/os y de la relación terapéutica disminuyendo estados de ansiedad. Las siguientes cuatro viñetas (Figuras 4-7) muestran estas funciones, desde la experiencia de las alumnas.

Viñeta 3. La respuesta artística que más me tocó fue la que hizo Rocío Teruel (Figura 4), cuando supervisé el caso de E. me impactó porque, además de sentirme personalmente reflejada, me pareció que recogía muy bien ese dificilísimo ejercicio constante que ella (la usuaria) hace para mantenerse en equilibrio. A la vez es una figura de gran belleza. La usuaria es una persona muy inteligente, sensible y cuida mucho su imagen (excepto cuando se encuentra mal, que se va al extremo opuesto). En una sesión posterior en la que ella dibujó una línea que dividía la hoja en dos, separando lo bueno de lo malo, la RA de Rocío me sirvió como metáfora para hablar del equilibrio y de cómo hacer esa línea más gruesa que una cuerda, para poder andar sobre ella con más seguridad (Rosanna García).

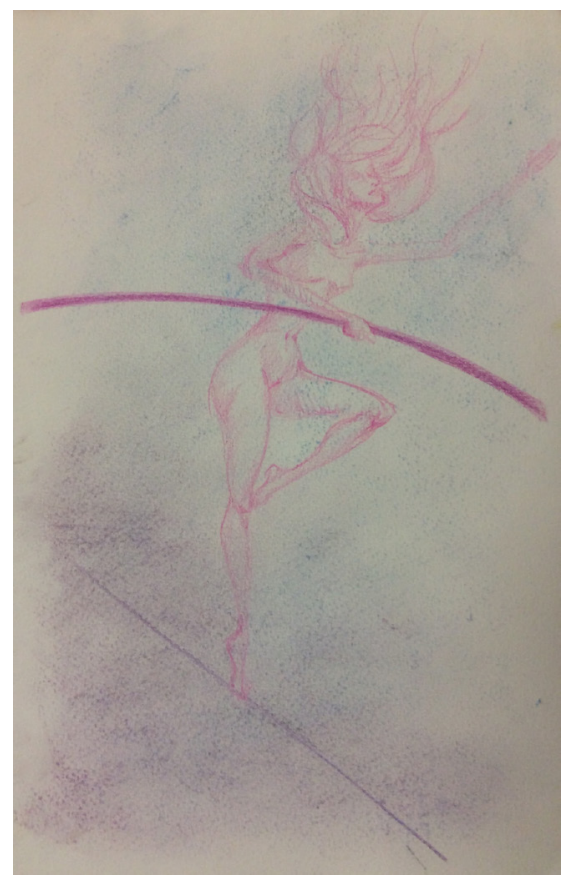

Figura 4. RA realizada por Rocío Teruel, en respuesta a la explicación del caso de Rosanna García.

Viñeta 4. En una fase inicial de la terapia me sentía algo impotente respecto a cómo acoger y contener una paciente. La respuesta de Marian Crespo (Figura 5) me ayudó a conectar con el hecho de que, aunque de forma algo insegura, sí que estaba conteniendo a mi paciente, y aunque el contenedor no me parecía perfecto, algo de 
sostén y acogimiento estaba proporcionando. Ya solo el poder ver esto me relajó, lo cual a su vez, imagino, me ayudó a poder contener mejor (Amaranta Amati).

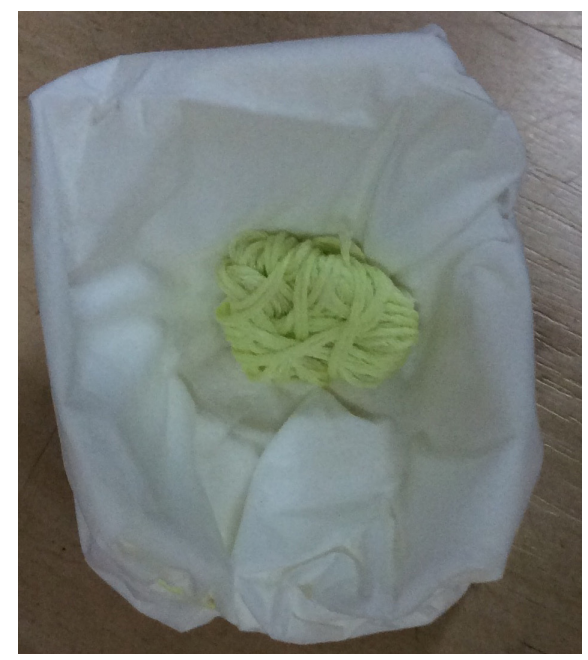

Figura 5. RA realizada por Marian Crespo, en respuesta a la explicación del caso de Amaranta Amati.

Viñeta 5. La obra respuesta que mas me resonó fue la tuya (supervisora), al ver la imagen (Figura 6) me quedé seducida. Pensé que parecía un nido muy confortable y muy bonito, casi idealizado. Ahí fue cuando empecé a interrogarme sobre la relación que estaba teniendo con L., si nos estábamos quedando las dos en un lugar cómodo, donde yo cuidaba a mi niña interior y donde ella se hacía cuidar. Y si eso, era algo, que le ayudaba a crecer (Marian Crespo).

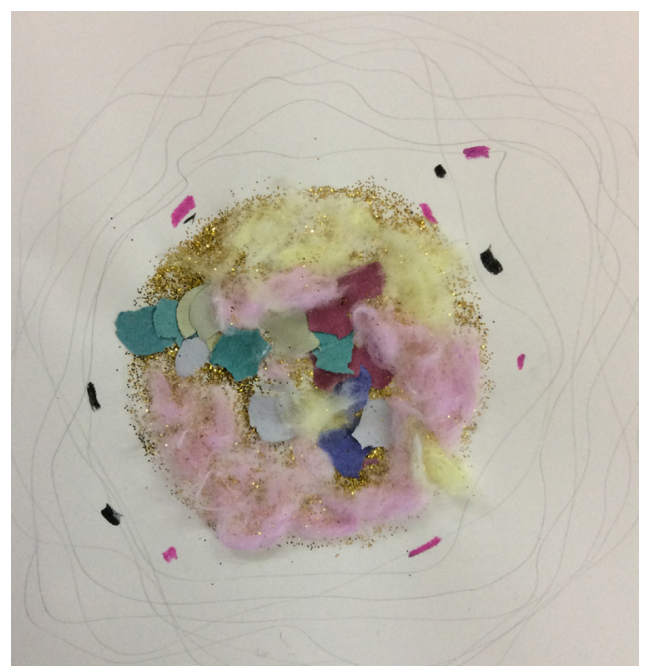

Figura 6. RA realizada por la supervisora, en respuesta a la explicación del caso de Marian Crespo. 
Viñeta 6. "Esta imagen de mi compañera Marian Crespo (Figura 7), me sirvió mucho, viéndola recuerdo con detalle el día de la supervisión. Representa perfectamente cómo estaba yo, me ayudó muchísimo con el caso de J.” (Elisa Villanueva).

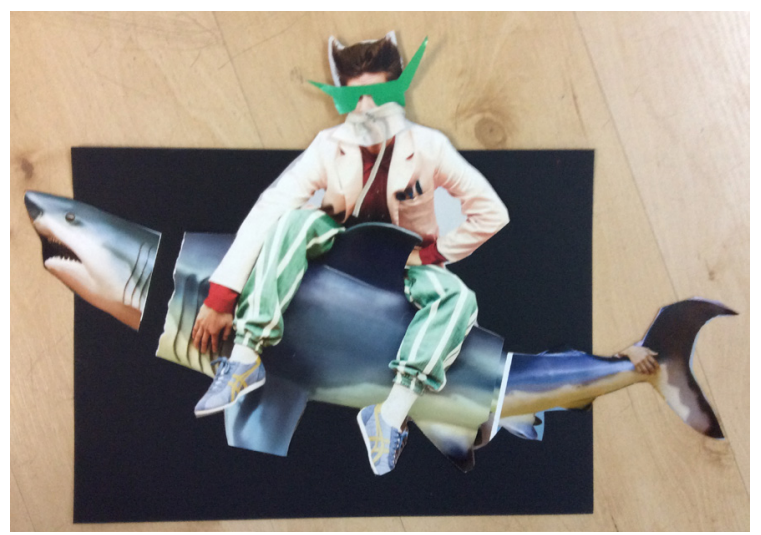

Figura 7. RA realizada por Marian Crespo, en respuesta a la explicación del caso de Alicia Villanueva.

Hubo una alumna que, a diferencia de sus compañeras, comentó: "En realidad, yo lo he experimentado un día en que no tenía tanta necesidad..." El uso de un calendario ayuda a asegurar que cada estudiante reciba un tiempo repartido de forma igualitaria, sin embargo puede ocurrir una situación como la descrita por esta estudiante, la falta de tiempo es un factor importante, resultando ser insuficiente en algunos de los casos.

Afirmación 4. Las RA que yo realicé para mis compañeras, para darles retroalimentación sobre su práctica clínica han sido de utilidad para mí.

"A veces me ha ayudado a entender mejor a mi compañera, cómo se sentía y por qué estaba lidiando con la situación de esta o aquella manera". El análisis mostró que para cuatro participantes fue un ejercicio útil para el desarrollo de la empatía, "pude ponerme en sus pieles"; también se observó de apoyo para generar el compromiso e implicación entre ellas, observándose tres respuestas al respecto; y para sentirse útiles y capaces de ofrecer una mejor intervención hacia sus compañeras.

Tres comentarios refieren confusión al respecto "A veces no sé qué comunicarles". Creo que esta confusión, puede tener que ver con el hecho de que es un ejercicio que requiere compromiso, la inseguridad como estudiante en prácticas está presente, esta herramienta nos ofreció la posibilidad de construir el conocimiento entre todas y de forma horizontal, un ejercicio que puede generar inseguridad.

Afirmación 7. Realizar trabajo artístico durante la supervisión quita un tiempo valioso para la discusión de otros aspectos.

"Me parece importante que cada una pueda decidir cómo invertir su tiempo de supervisión. A veces es necesaria una discusión ... otras veces es muy interesante recibir una RA...". La mayoría de las respuestas mostraron una tendencia positiva a valorar la creación de RA dentro del espacio de supervisión, seis comentarios refieren esta metodología como necesaria, complementaria, valiosa y útil como una herramienta de comunicación no verbal. Sin embargo, en dos respuestas se señalan la importancia 
del tiempo como factor a valorar a fin de recibir la información necesaria para aclarar sus dudas. Cuatro respuestas hacen referencia a la importancia de tomar en cuenta las necesidades de la supervisada para llevar a cabo una SBA o de carácter verbal.

Pregunta 8. ¿Podrías decir 4 ventajas de realizar $R A$ como apoyo de tu práctica como arteterapeuta en formación?

"Me ayuda a analizar mi práctica. Aclara mis sentimientos. Contratransferencia y transferencia". En la tabla 2 se muestran todas las respuestas a esta última pregunta. El análisis mostró diferentes usos de la SBA, entre los que destacan: la utilidad como herramienta de autocuidado y apoyo emocional, referido por cinco personas, "descarga de la tensión y acumulación de contratransferencia..."; de soporte en el desarrollo de la empatía; útil para la comprensión y análisis de la práctica clínica para cinco personas en cada categoría: "Es terapéutico... una forma de "entrar en el mundo del otro... y poder aportar algo"

Cuatro estudiantes la valoraron como herramienta clarificadora, útil para volver el material inconsciente en consciente, generadora de insights; para la descarga de emociones, nombrando una de ellas la obra como "contenedora de emociones difíciles"; cinco participantes valoraron las obras físicas como un registro visual de lo sucedido, refirieron también que la RA fue útil para recordar la sesión con sus usuarias/os y el mantenimiento de la identidad como artista.

Tabla 2. Cuatro ventajas de realizar RA como apoyo a las prácticas clínicas en la formación. Respuestas de las alumnas.

\section{¿Podrías decir 4 ventajas de realizar respuesta artística como apoyo de tu práctica como arteterapeuta en prácticas?}

\section{Participante 1}

1. Recordar con mayor facilidad lo sucedido.

2. Expresar como te sientes después de esa sesión (a veces te afecta más o menos).

3. Cuando ha acabado el curso, ves el seguimiento del paciente en las obras tanto de la persona como la nuestra, es como un recorrido, es difícil de expresar en palabras, ver la evolución, el cambio.

4. Cuando estas en una sesión, también se puede considerar que tu estás en terapia, por lo tanto, a mi modo de ver es necesario hacer también una obra (aunque sea del resumen de la sesión).

\section{Participante 2}

1. Me ayuda a analizar mi práctica.

2. Aclara mis sentimientos.

3. Contratransferencia y transferencia.

\section{Participante 3}

1. Me ha ayudado a entender mejor a los usuarios y a mi misma.

2. Realizar respuestas artísticas en un grupo de supervisión es una experiencia muy enriquecedora por los diferentes puntos de vista de los participantes al grupo, y ha sido muy interesante poder ver como cada unas de nosotras ha expresado artísticamente lo que quien supervisaba transmitió.

3. Es terapéutico.

4. Es una forma de "entrar en el mundo del otro", ponerse en su piel, sentir lo que sintió en la sesión y poder aportar algo para clarificar dudas. 


\section{Participante 4}

1. Descargar: una transferencia recibida o una acumulación de mi contratransferencia... descargar la tensión de la sesión.

2. Elaborar sensaciones, intuiciones, insghts no conscientes. la elaboración de mi obra respuesta me ayuda de forma no racional a elaborar 'algo' del cual solo llego a ser consciente, a poderlo entender, al mirar mi obra respuesta.

3. La cara oscura de la sesión: a veces en las obras de los pacientes no están presentes elementos muy fuertes y perturbadores que fueron parte integrante de la sesión, mi respuesta artística a veces registra la 'cara b' de la sesión.

4. Imitación: que estará viviendo mi paciente? a veces hacer una obra respuesta que imita un movimiento/el uso de unos colores/la dificultad de crear un objeto me ha permitido acercarme a (quizás?) la vivencia de mis pacientes. Es muy útil. la verdad.

\section{Participante 5}

1. Comunicación de temas difíciles.

2. Formación de vínculos de empatía.

3. Apoyo emocional.

4. Defensa personal.

\section{Participante 6}

1. Reduce la ansiedad.

2. Ayuda a procesar la sesión.

3. Insight.

4. Comprender tu estado de ánimo durante la sesión.

\section{Participante 7}

1. Ampliar mirada.

2. Abrir la puerta a la intuición.

3. Conectar con tu contratransferencia de forma menos intelectualizada.

4. Compartir con las compañeras de supervisión cosas difíciles de explicar.

\section{Participante 8}

1. Hace que conozcas como te sientes, no pasar por encima.

2. Me ayuda a entender el usuario mejor.

3. Una manera de seguir contacto con el material y el crear, aunque pequeño o corto.

4. Es algo que también puedes compartir con supervisoras/compañeras/os, y puede ayudar a explicar como lo vives mas allá de las palabras.

\section{Participante 9}

1. Te ayuda a estar más atenta a lo que has sentido durante las sesiones.

2. Queda un registro visual de lo que ha supuesto para ti cada sesión.

3. En el futuro te da la oportunidad de comparar las notas y las obras.

4. A tener una visión más global.

\section{Participante 10}

1. Contacto con el inconsciente.

2. Cuidar nuestros sentimientos difíciles.

3. Ganar más empatía hacia nuestros compañeros/as y pacientes.

4. Documentación de lo que ha pasado dentro como guía. 


\section{Participante 11}

1. Crear obra respuesta me ayudó a ver la situación desde un ángulo diferente.

2. Compartir la obra respuesta dirigida para una compañera de clase me ayudó a expresarme mejor. Realmente no conocemos bien la situación del otro, pero tenemos muchos sentimientos cuando la persona está presentando su caso, por lo tanto, podemos compartir cómo nos sentimos a través de la respuesta artística.

3. Para mí, crear después de las sesiones me ayudó a comprender cómo a veces el cliente puede haber sentido durante la sesión.

4. También me ayudó a recordar las sesiones. No siempre podía recordar después de leer algunas notas incluso tomaba notas después de cada sesión, pero después de mirar la respuesta artística de las sesiones, siempre podía recordar de qué se trataba la sesión.

5. ...Estoy tan contenta de haber tenido esta experiencia y la oportunidad de explorar mi práctica clínica de esa manera.

\section{Discusión}

De forma general se pudieron observar seis usos básicos de la SBA:

1. Desarrollo de la empatía hacia las integrantes del grupo y hacia las/los usuarios.

2. Apoyo en la comprensión y análisis de la práctica clínica.

3. Apoyo emocional como herramienta de autocuidado.

4. Clarificadora de elementos preconscientes, llevándolos a la consciencia.

5. Útil como registro visual de lo ocurrido.

6. De apoyo y complemento en la comunicación.

En su mayoría, los comentarios de las estudiantes sugieren que esta modalidad de aprendizaje fue útil en nuestro contexto educativo. Observando al igual que otras autoras y autores que fue de ayuda en el autocuidado (Brown, Meyerowitz-katz y Ryde, 2003; Fish 2012; Marano-Geiser, 1990; Miller y Robb, 2017; Moon, 1999); autoconocimiento, en el aprendizaje de su formación como futuras arteterapeutas (Fish, 2008; McNamee y McWey, 2004; Miller y Robb 2017; Miller, 2012); de ayuda en el desarrollo de empatía hacia compañeras y al igual que describe Kielo (1988) de apoyo para fomentar la empatía hacia los/las usuarios/as.

Se pudo observar que esta experiencia de trabajo animó a la reflexión y profundización de sus prácticas como mencionan otras/os arteterapeutas (Crawford, Solis y Pfister, 2014; Fish, 2008; Miller, 2017; Wadeson, 2003), siendo la RA catalizadora para discusiones dentro del espacio de supervisión; para revelar el contenido latente de la experiencia clínica y para darse cuenta de su capacidades y puntos ciegos. Ofreciendo también una forma de cuidar la comunicación entre las integrantes.

Por otro lado, hubo algunas respuestas que indicaban el deseo de una supervisión con mayor discurso verbal. Al igual que Fish (2008), considero que la creación de las imágenes y su uso durante la supervisión puede no ser adecuado para todas las personas, dependerá de las necesidades de aprendizaje personal, el cual es un proceso único. Dos alumnas consideraron que realizar RA dentro del espacio de supervisión, quitaba un tiempo valioso para la exploración de dudas; una alumna consideró que 
en el momento en el que recibió RA no lo necesitaba y algunas estudiantes hicieron referencia a la necesidad de más tiempo para la resolución de aspectos clínicos.

En cuanto al hecho de crear RA junto a sus compañeras, no obtuvimos respuestas negativas con respecto a la falta de confianza para crear juntas y/o mostrar RA; algo si observado en el trabajo de Fish (2008). Siguiendo las sugerencias de esta autora, como ya se menciona en el apartado de metodología, la modalidad de SBA en este estudio, fue iniciada a partir del tercer mes del inicio del curso; favoreciendo a desarrollar la confianza grupal.

Inicialmente prevaleció un formato didáctico de discusión verbal sobre la prácticas, apoyada con las imágenes creadas por clientes y de RA realizadas por las alumnas fuera del espacio de supervisión, resultando efectivo en esta primera etapa en la que las estudiantes pueden sentirse más vulnerables. Se buscaba como menciona Miller et. al. (2017), promover las alianzas dentro del ambiente grupal, en un intento conseguido de nutrir la capacidad de tener el valor de exponer sus vulnerabilidades; cometer errores y asumir riesgos, los cuales son claves para el crecimiento clínico.

Las alumnas pudieron tomar consciencia del modo en el que las RA recibidas fueron de ayuda para desarrollar el autoconocimiento y la reflexión. Aunque algunas estudiantes refirieron inseguridad o desconocimiento en cómo, su propia RA puede ayudar a sus compañeras, para otras fue un ejercicio en el que se sintieron útiles, ayudando también a sustentar su capacidad de empatía entre ellas.

\section{Conclusiones}

Dirigir la mirada hacia arteterapeutas de países donde hay más años de experiencia, puede ser un puente que facilite la profesionalización de arteterapia en España. Aprender de sus hallazgos, de sus errores y seguir sus modelos de trabajos puede ser de utilidad para nuestra práctica.

El valor del arte en supervisión es innegable, especialmente en nuestra profesión, puede ofrecer una manera de explorar; contener y expresar el trabajo clínico, dando lugar a un vasto cocimiento. Sin embargo, es importante encontrar el equilibrio entre la creación artística y la supervisión clínica verbal, a fin de que el tiempo disponible sea suficiente para la resolución de dudas clínicas. Ninguno de los dos debe ser descuidado.

Es importante tomar en cuenta las necesidades particulares de las/los alumnas/os, ofreciendo un tipo de supervisión que sea adecuada para cada momento particular, resolver las dudas clínicas es el objetivo principal de la supervisión como arteterapeutas. Si encontramos el equilibrio entre estas dos partes será la clave del éxito como supervisoras/es en arteterapia.

Haber realizado RA al lado de las alumnas supervisadas fue una práctica grata y reveladora, me posicionó en una línea horizontal con respecto a las supervisadas, y desde allí fue más fácil construir el conocimiento juntas y vivir una experiencia de retroalimentación, donde buscamos el conocimiento a través de la creación artística, todas juntas pensando y explorando a través del arte el ejercicio clínico de una ellas, donde lo más importante fue la persona usuaria y la supervisada.

Espero que este trabajo sea útil para nuestra práctica profesional. 


\section{Limitaciones}

Este estudio cuenta con una muestra muy pequeña (11) y la falta de un grupo de control. La recogida de datos ha sido realizada por mi, lo más adecuado hubiera sido, que fuera hecha por otra persona. No ha sido evaluado el hecho de que yo, como supervisora, haya creado RA junto a las supervisadas; sería interesante conocer las opiniones de las estudiantes al respecto. Para próximos trabajos sería conveniente tomar en cuenta lo expuesto.

\section{Agradecimientos}

De manera muy especial agradezco a las estudiantes que participaron en este proyecto, sin ellas no hubiera sido posible su realización, gracias por su colaboración, implicación y tiempo empleado, ha sido un honor y un placer trabajar a su lado. A Barbara Fish y a Abbe Miller, la lectura de sus trabajos han sido mi principal fuente de inspiración. Gracias a Lucía Hervás Hermida por su apoyo en el análisis de datos cualitativo, ofreciendo mayor calidad al trabajo.

\section{Referencias}

Allen, P. B. (1995). Art is a way of knowing. Aguidetoself-knowledge and spiritual fulfillment through creativity. Boston, MA: Shambhala.

Berger R (2017). Shifting roles: A new art based creative supervision model. The Arts in Psychotherapy, 55 158-163, DOI: https://doi.org/10.1016/j.aip.2017.04.010

Brown C., Meyerowitz-katz J. \& Ryde J.(2003). Thinking with image making in supervisión. Inscape, 8:2, 71-78, DOI: 10.1080/17454830308414056

Carpendale, M. (2011). Stopping to paint on the journey: Art-based supervision. En: A Traveler's Guide to Art Therapy Supervision. Victoria BC: Trafford Pub. DOI: $10.1080 / 02647140408405680$

Crawford, S., Pfister E., \& Solis G. (2014). Art making for the art therapist: A study on clinical insight, therapist identity, self care, and countertransference. LMU/LLS The- ses and dissertations. 54. Recuperado de: http://digitalcommons.lmu.edu/etd/54

Deaver S. \& Shiflett Ch. (2011). Art-Based Supervision Techniques. The Clinical Supervisor, 30:2, 257-276, DOI: 10.1080/07325223.2011.619456

Fish, B. (2008). Formative evaluation research of art-based supervision in art therapy training. Art Therapy: Journal of the American Art Therapy Association, 25, 70-77.

Fish, B. (2012). Response Art: The Art of the Art Therapist. Art Therapy: Journal of the American Art Therapy Association, 29 (3), 138-143.

García Lorca F. (2003). Juego y teoría del duende. Editorial del cardo. Buenos Aires. http:// www.biblioteca.org.ar/zip22.asp?texto $=1001888$

García-Reyna, N. (2017). Orígenes de Arteterapia en España. Entrevista a Carles Ramos. $L a$ Revista de Arteterapia de Metáfora, 1:1, 4-9.

García-Reyna, N. (2017). Respuesta Artística de Arteterapeutas. La Revista de Arteterapia de Metáfora, 1:1, 18-28, DOI:

Gilroy, A (1989). On Occasionally Beig able to paint. Iscape, Spring 2-9

Gordon, R (1992). Supervision, ponencia presentada en un congreso. 'The Practice of Supervision: Some Contributions', British Association of Psychotherapists, London. 
Guiffrida, D., Jordan, R., Saiz, S. \& Barnes, K. (2007). The use of metaphor in clinical supervision. Journal of Counseling \& De-velopment, 85, $393-400$.

Hervás Hermida, L. (2018). Arteterapia para la maternidad y la familia. Una vía de apoyo a la parentalidad positiva. Tesis doctoral. Universidad Autónoma de Madrid. Recuperado de: https://repositorio.uam.es/handle/10486/686100

Huet, V. (Septiembre 2016). Seminario de teoría de la Supervisión en Arteterapia. Metáfora. Escuela de Arte y Arte contemporáneo. Barcelona.

Kielo, J. B. (1988). A study of art therapists' countertransference and post session imagery. Tesis de máster. Concordia University. Recuperado de: http://spectrum. library.concordia. $\mathrm{ca} / 4668 /$

Kramer, E. (1986). The art therapist's third hand: Reflections on art, art therapy, and society at large. American Journal of Art Therapy, 24(3), 71-86.

Malchiodi, C. A., \& Riley, S. (1996). Supervision and related issues: A handbook for professionals. Chicago, IL: Magnolia Street.

Marano Geiser M.A., A.T.R. (1990). Through the Looking Glass: II. Impact on the Artist Self. Art Therapy: Journal of the American Art Therapy Association, 7:3, 110-113, DOI: 10.1080/07421656.1990.10758903

Marxen E. (2011). Diálogos entre arte y terapia. Del "arte psicótico" al desarrollo de la arteterapia y sus aplicaciones. Editorial Gedisa, Barcelona.

McNamee, C. M., \& McWey, L. M. (2004). Bilateral art to facilitate clinical supervision. The Arts in Psychotherapy, 31(4), 229-243.

Miller, A. (2012). Inspired by el duende: One-canvas process painting in art therapy supervision. Art Therapy: Journal of the American Art Therapy Association, 29(4), 166173. DOI: $10.1080 / 07421656.2013 .730024$

Miller, A., \& Robb, M. (2017). Transformative phases in el duende process painting artbased supervisión. The Arts in Psychotherapy, 54 15-27, https://doi.org/10.1016/j. aip.2017.02.009

Moon, B. L. (1999). The Tears Make Me Paint: The Role of Responsive Art Making in Adolescent Art Therapy. Art Therapy: Journal of the American Art Therapy Association, 16(2), 78-82 DOI: 10.1080/07421656.1999.10129671.

Omenat, M. (2011). La supervisión en Arteterapia. Conferencia presentada en II Jornada FEAPA (Federación Española de Asociaciones Profesionales de Arteterapia). Convent de Sant Agustí. Barcelona. En http://arteterapia.org.es/supervision/

Ramos, C. (marzo 2010). Diario de imágenes. I Congreso Nacional de Arteterapia (FEAPA). Las voces de la profesión y sus campos de intervención. Girona, España.

Rogers, M. (2002). Absent figures: A personal reflection on the value of art therapists own image-making. INSCAPE, 7:2, 59-71, DOI: 10.1080/17454830208414044

Serrano A. (2017). Reflexiones acerca de la supervisión en Arteterapia. Ateterapia. Papeles de arteterapia y educación artística para la inclusión social,12, 299-300.

Shaverien, J. \& Case (1992). The Revealing image: analytical art psychotherapy in theory and practice. London: Routledge.

Wadeson, H (2003). Making art for professional processing. Art Therapy: Journal of the American Art Therapy Association, 20 (4), 208-218 